\title{
A lepra na perspectiva médica: Antônio Justa e o saber médico sobre a lepra no Ceará (1930)*
}

The leprosy in medical perspective: Antônio Justa and the medical knowledge about the leprosy in Ceará (1930)

\author{
Francisca Gabriela Bandeira Pinheiro \\ Mestre em História \\ pela Universidade Estadual do Ceará \\ gabrielabandeira@live.com
}

\begin{abstract}
Resumo: Antônio Justa foi um médico cearense que se envolveu no combate à lepra no Ceará através dos seus discursos e práticas. Com a fundação do primeiro leprosário do Estado, em 1928, Justa começou a realizar o atendimento médico aos doentes da instituição e de Fortaleza. A partir desse momento, iniciou a sua escrita na imprensa cearense, com destaque para a doença sob o ponto de vista médico. Em 1930, publicou sua primeira série de artigos com a intenção de esclarecer alguns pontos sobre a doença, pois ficou surpreendido com a falta de conhecimento sobre ela. Dessa forma, Justa passou a produzir um saber sobre a lepra e esses artigos são importantes para conhecer as bases desse conhecimento, que foi abordado por Antônio Justa até sua morte.
\end{abstract}

Palavras-chave: Saber médico, Antônio Justa, Lepra.

\begin{abstract}
Antônio Justa was a doctor of Ceará who was involved in the fight against leprosy in Ceará through their speeches and medical practices. With the founding of the first leprosarium of the State, Justa began to perform medical care to patients of the institution and Fortaleza. From that moment, the doctor began writing in Ceará press, especially the disease from a medical point of view. In 1930, the doctor published his first series of articles with the intention of clarifying some points on the medical condition, because he was surprised by the lack of knowledge about it. In this way, Justa went on to produce a medical knowledge about leprosy and this first series of articles is important to know the basis it was approached by Antônio Justa until his death.
\end{abstract}

Keywords: Medical knowledge, Antônio Justa, Leprosy.

* Financiamento da pesquisa: Fundação Cearense de apoio ao desenvolvimento científico e tecnológico (FUNCAP). 


\section{Introdução}

Segundo Antônio Ferreira (2011), os primeiros registros sobre a lepra no Ceará começaram ainda no século XIX. Porém, as ações de combate a essa doença só foram mais efetivas no início do século XX, já que foi no desenrolar do início do século passado que a doença passou a ser mais vista, tanto pela imprensa, que se alarmava para o perigo da lepra, como pelos poderes públicos, que embora tivessem pouca atuação, desenvolveram algumas ações nesse sentido.

Em 1918, ocorreu a tentativa de um plano de combate à lepra no Ceará, por parte do médico Carlos Ribeiro, então Diretor de Higiene do Estado, que visava o isolamento de leprosos como a melhor forma de se combater a enfermidade, pois acreditava no alto grau de contágio da doença. Entretanto, o referido plano não recebeu muitos adeptos, sendo realizadas apenas algumas ações pontuais (FERREIRA, 2011). Dessa forma, esse plano pode ser considerado uma das primeiras ações no sentido de isolar os doentes de lepra do Estado.

Na década de 1920, a lepra volta a ser motivo de destaque, não só localmente, mas nacionalmente, através da aprovação do Regulamento Sanitário Federal de 1923, que colocava a lepra como doença cujo isolamento era obrigatório (CUNHA, 2005) e da fundação da Inspetoria de Profilaxia da Lepra e Doenças Venéreas (IPLDV), subordinada ao Departamento Nacional de Saúde Pública (DNSP), criados em 1920:

A Inspetoria de Profilaxia da Lepra e das Doenças Venéreas estava diretamente subordinada à Diretoria Geral do Departamento [Nacional de Saúde Pública] e sob a chefia do dermato-sifilógrafo Eduardo Rabello. Tinha por finalidade superintender e orientar o serviço de combate à lepra e às doenças venéreas em todo o território nacional, e o de combate ao câncer no Distrito Federal, embora este não aparecesse na nomenclatura oficial (CUNHA, 2005: 51).

No Ceará, a IPLDV criou o Serviço de Profilaxia da Lepra e Doenças Venéreas (SPLDV) em agosto de 1921. Porém, a atuação do referido serviço foi diminuta, pois este se dedicou mais ao combate à sífilis. As poucas ações de combate à lepra, no período citado, foram feitas pelo Serviço de Profilaxia Rural, como a fundação do 
dispensário Oswaldo Cruz, em 1922, e a feitura de um censo de leprosos no Estado (LIMA, 2007).

A imprensa, todavia, tomou para si o problema da lepra e começou a relatar constantemente a necessidade de isolar os leprosos, principalmente o jornal O Nordeste, periódico católico que, desde a sua fundação em 1922, se debruçou sobre o problema da lepra no Ceará, destacando o quanto era necessário à construção de um leprosário no Estado:

O jornal O Nordeste, ainda em seu primeiro ano de circulação, em 1922, já traz em suas páginas um considerável espaço para a questão do leprosário no Ceará. As matérias publicadas no periódico durante 1922 refletem, principalmente, certo descontentamento por parte do jornal pela falta de ação governamental no combate à lepra e também já menciona e defende, ainda timidamente, a necessidade de criação de uma leprosaria no estado do Ceará como forma de controle da doença (PINHEIRO, 2013: 49).

Devido, em grande parte, às ações do periódico em conjunto com a sociedade, foi fundado em 1928, em Redenção, no distrito de Canafistula, a $80 \mathrm{~km}$ de Fortaleza, o leprosário de Canafistula, posteriormente renomeado para Antônio Diogo, com a intenção de isolar os leprosos do Estado. É também diante desse contexto que o médico Antônio Alfredo da Justa começa a desempenhar um papel de maior destaque na sociedade cearense, principalmente no combate à lepra.

\section{O início da atuação de Antônio Justa no combate à lepra}

Em 1881, na cidade de Fortaleza, nasceu Antônio Alfredo da Justa, filho de Laura Teófilo da Justa e Alfredo Henrique da Justa. Décadas mais tarde, o então menino se tornaria o Dr. Antônio Justa, médico que possuiu bastante destaque no Ceará através das suas ações e discursos em torno da lepra (MOTA, jan/mar 1952).

Antes de começar seus estudos em Medicina, Antônio Justa foi morar na Paraíba, ainda criança, e retornou ao Ceará, por intermédio do seu tio e padrinho Rodolfo Marcos Teófilo, para estudar no Liceu do Ceará. Também incentivado por Teófilo, Justa iniciou seus estudos em Medicina, concluindo a sua formação em 1906, 
na cidade do Rio de Janeiro. Após formado, exerceu a profissão em Quixadá, cidade do interior do Ceará, mas não teve destaque na sociedade durante essa passagem, partindo para Santarém, no Pará. No início da década de 1920, Justa voltou para o Ceará, fixando residência na cidade de Fortaleza, onde abriu um consultório médico (MOTA, jan/mar 1952).

Com esse retorno ao Estado, Justa passou a se relacionar com os médicos cearenses, inclusive com o seu órgão de classe, o Centro Médico Cearense (CMC) e também com a saúde pública do Estado, assumindo inclusive cargos nos órgãos relacionados. Já em 1925, Justa conseguiu o cargo de subinspetor sanitário rural, no Serviço de Profilaxia Rural (SPR), função que desenvolveu até 1930. Através da atuação nesse órgão, Justa iniciou o seu contato maior com a lepra, pois foi encarregado de realizar o censo da doença no Ceará:

Há cerca de um ano encarregado do Censo da Lepra no Estado do Ceará, como funcionário do Serviço de Saneamento Rural, temos visto além de duas centenas de lázaros e nos postos mais diretamente em relação, através de leituras e da observação clinica com essa moléstia. Muito embora desde que iniciamos o nosso tirocínio clinico, vez por outra passasse sob os nossos olhos um caso de lepra, fosse na clínica de consultório, fosse na domiciliar, tendo ademais trabalhado cerca de dez anos no Baixo Amazonas, onde é notória a frequência do Mal de Hansen, somente agora mais estreitamente nos temos dedicado ao seu estudo [...] (JUSTA, set/out 1929:2)

Como foi apontado, devido a uma atenção maior para a lepra, principalmente por parte da imprensa, ocorreu a inauguração da primeira instituição de isolamento de leprosos do Ceará em 1928. Antônio Justa, como estava envolvido com as pesquisas sobre a lepra através do censo que estava realizando, acabou ficando responsável pela referida instituição, através da função de diretor clínico, em que fazia o atendimento médico através de visitas regulares ao local. Desse modo, o médico receitava medicação, diagnosticava casos, preenchia prontuários médicos, fazendo o histórico da doença e descrevendo os sintomas e sinais de cada paciente, bem como o comportamento na instituição. Além disso, o médico também fazia o atendimento aos leprosos de Fortaleza. 
A trajetória de Antônio Justa no combate à lepra não se resume apenas a sua prática no atendimento aos doentes, pois ele procurou estudar a respeito de tal enfermidade e passou a difundir o conhecimento que acumulava sobre a doença através de publicações na revista Ceará Médico. O primeiro artigo de Justa encontrado na referida revista é de 1929 e o médico já demonstrava o seu interesse em estudar a doença e a sua intenção de divulgar o saber médico que adquiria a respeito dela.

\section{O saber médico de justa sobre a lepra no Ceará}

A grande motivação para o início da pesquisa e da escrita médica sobre a doença surgiu, segundo o próprio médico, devido à surpresa em relação ao grande número de: “[...] preconceitos e de conhecimentos arcaicos, gozando foros de atualidade, existem sobre tal moléstia, até mesmo no seio das classes eruditas" (JUSTA, set/out 1929: 2). O referido trecho é do primeiro artigo de Justa publicado na Ceará Médico sobre a lepra e, nesse texto, além de comentar suas motivações para o estudo da doença, aponta um caso que chamou bastante a sua atenção e gerou o seu interesse na difusão de um conhecimento sobre a lepra. Trata-se de um doente de lepra não-contagiante que cometeu um assassinato, sendo descrito como um perturbado mental. Devido a sua condição de ser um leproso, o homem passou a ser rejeitado nas instituições que deveriam cuidar dele, essas eram: a santa casa, o asilo de alienados e a cadeia pública, sendo sugerido que o doente fosse encaminhado para o leprosário, que não possuía uma cadeia no período, o que acabou acontecendo. Justa achou a situação absurda e comentou:

Infelizmente contra o desgraçado agia o terror pânico da morfeia, sobrepujando o instinto de humanidade mais elementar, sobranceiro até aos interesses da Sociedade, justamente agravada pelo seu crime! Emocionados com este fato e com vários outros menos dramáticos, mas nem por isto menos impressionantes, foi que resolvemos escrever estas despretensiosas considerações sobre a Lepra, principalmente sobre sua Epidemiologia, Sintomalogia e Diagnóstico, Tratamento e Profilaxia. Fruto das nossas leituras o que se vai ler, acrescentado também será do que tivermos colhido da nossa observação, ainda que diminuta, todavia conscienciosa (JUSTA, set/out 1929: 4) 
Dessa forma, a partir do caso citado, Justa sentiu necessidade de conscientizar a sociedade sobre a lepra e assim o fez, tendo publicado, durante o ano de 1930, sete artigos na revista Ceará Médico sobre as temáticas citadas no trecho acima. Essa série de artigos trata dos primeiros pensamentos e conhecimentos construídos por Justa acerca da doença e já apontava muitas informações relevantes e modernas no que se refere à lepra, além de trazer ideias substanciais para a construção de um real saber médico sobre a lepra no Estado.

Diante disso, considera-se que foi a partir da produção desses artigos que começou a ser desenhado um saber médico sobre a lepra no Ceará, sendo encabeçado por Antônio Justa, através das suas leituras e experiências sobre a doença.

O primeiro artigo encontrado já aponta pontos muito interessantes acerca da lepra e que já vinham sendo debatidos nacionalmente, como, por exemplo, as teorias sobre a forma de propagação da doença: se por contágio direto, do indivíduo doente para o sadio; indireto, através de vetores, geralmente um mosquito; ou hereditária, ou seja, transmitida do doente para a sua descendência (JUSTA, maio 1930). Nacionalmente falando, as três teorias tinham os seus partidários, mas a teoria do contágio direto foi ganhando cada vez mais força entre os médicos (FERREIRA, 2011). Justa, em seu artigo, apesar de descrever as diferentes teorias sobre a lepra, inclusive fazendo um breve histórico de cada uma, demonstra-se mais partidário da teoria do contágio direto e justifica sua postura através da experiência com os leprosos do Ceará: “Ora, adoeceu em primeiro lugar o rapaz, depois o pai quase concomitantemente várias das moças e própria mãe. A irmã mais velha escapou ao contágio por se ter retirado cedo do seio da família, em virtude de se ter casado. Vulgar é o caso de um só leproso em família numerosa." (JUSTA, maio 1930: 13).

Porém, o médico vai mais além, levantando a ideia de que a lepra não é uma doença tão contagiosa como se tem pensando no Estado, já que, segundo um estudo do professor americano Leonard Rogers, apenas 3 a 5\% das pessoas que partilham um contato com uma pessoa leprosa contraem a doença (JUSTA, maio 1930). Dessa forma, Justa, em outro texto dessa série de artigos, afirma:

De tudo se conclui que o contágio da Lepra se PROCESSA DE MANEIRA MUITO LENTA, em regra mediante PROLONGADO CONTATO, e requer condições ESPECIAIS DE RECEPTIVIDADE, tendo-se em vista à 
fragilidade extrema do MYCO-BACTERIUM LEPRAE no meio ambiente, evidenciada pela sua incultivabilidade e rara transmissibilidade aos animais de laboratório e ao próprio homem, em INOCULAÇÃO EXPERIMENTAL (JUSTA, out 1930: 18).

Além disso, o médico aponta que doentes com B.H negativo não estão transmitindo a doença, ou seja, não são contagiantes (JUSTA, maio 1930:16) e conclui sua ideia afirmando "a Lepra é a menos contagiosa, das moléstias contagiantes" (JUSTA, maio 1930:16). Ou seja, com relação à forma de propagação da doença, Justa constrói um saber médico baseado na ideia de que a lepra não é sinônimo de perigo, como vinha sendo retratada pela imprensa e que, com os devidos cuidados, era possível diminuir a propagação da doença, já que era o contato íntimo e prolongado que criava condições de receptividade para a lepra (JUSTA, maio 1930:16).

No Brasil, com essa teoria, Justa não estava sozinho, pois existiam outros médicos contemporâneos seus que também acreditavam na teoria do contágio direto, mais íntimo e prolongado, como Eduardo Rabello:

O ponto fundamental que o médico buscava reforçar dizia respeito ao grau de contagiosidade da lepra que, de acordo com a observação e a estatística, demonstrava ser baixa. Defendia que a doença era pouco contagiosa e o seu contágio operava-se, em geral, mediante um contato íntimo e prolongado com o doente. (SOUZA, 2009: 62).

Justa, dessa forma, começou construindo um conhecimento sobre a lepra que já estava em debate no restante do Brasil, mostrando estar atualizado das discussões a nível nacional. Porém, mesmo assim, se tratava de um conhecimento inovador para a época, já que a lepra, durante muitos anos, continuou sendo vista como extremamente contagiosa, em menor escala, pelos médicos, mas em maior escala pela imprensa leiga.

Nos dois artigos referentes à sintomalogia e diagnóstico da lepra, o médico aponta os principais sintomas da doença, afirmando que, geralmente, ela pode ser facilmente reconhecida, inclusive por pessoas leigas, devido aos sinais serem claramente percebidos: 
Inúmeros são os casos que temos examinado, notificados por leigos até analfabetos, tendo sempre a confirmação clínica e microscópica do nefando mal! Dezenas de doentes, enviados dos vários municípios do Interior, notificados por pessoas estranhas à Medicina, se acham recolhidos ao "Leprosário Antonio Diogo" em Canafistula, e nunca tivemos ocasião de contestar um diagnóstico (JUSTA, jun 1930:16).

Porém, mesmo assim, o médico afirma que alguns casos exigem mais atenção, pois a pessoa pode estar doente mesmo sem apresentar muitos sintomas e sinais característicos de lepra, o que exige grande cautela por parte do médico e ainda depende da "boa vontade" do doente para não esconder os sintomas embaixo das roupas, facilitando o diagnóstico médico. Inclusive ele aponta que também é possível que a doença seja confundida com outras enfermidades, como sífilis, tuberculose cutânea e dermato-micoses (JUSTA, jul 1930).

Com relação ao artigo referente ao tratamento, Justa se mostra atualizado sobre o que ele chama de fase científica da lepra, pois considerava que os trabalhos recentes dos cientistas ingleses e norte-americanos possibilitavam uma nova forma de se tratar a lepra. Ele aponta o quanto o tratamento da doença era deficitário antes do aparecimento da nova medicação:

Era a época em que leigos e profissionais se davam as mãos, no vulgarizar de toda maneira as mais esdrúxulas formulas medicamentosas, hauridas em todos os reinos da Natureza, levando a esperança breve desvanecida, aos infelizes lázaros. Todo medicamento novo, útil a esta ou aquela moléstia, logo era ensaiado na Lepra e si havia a coincidência de uma melhora espontânea, então o erro ou o engano e,sobretudo, o engodo, tinham mais longa duração (JUSTA, ago 1930:16).

Percebe-se que Justa descreve uma fase baseada no experimentalismo no que se refere ao tratamento da lepra e, para o médico, os recentes avanços científicos apontavam um novo caminho para a terapêutica anti-leprótica. Esses avanços citados por Justa são os medicamentos baseados no óleo de chaulmoogra, que são bem vistos pelo médico, apontando os bons resultados que foram conseguidos no mundo devido ao uso do medicamento e dos seus derivados. Ao falar do medicamento, Justa utiliza a 
opinião de médicos e cientistas, um dos mais citados é o leprólogo Rogers, pois Justa cita diversas estatísticas feitas por ele para embasar o seu discurso (JUSTA, set 1930).

Justa afirma que utiliza a medicação em seus pacientes, mas que ainda não pode trazer nenhum resultado estatístico, pois sua experiência com ela é relativamente pequena, mas, mesmo assim, afirma: “[...] já possamos agora apresentar vários dos nossos doentes evidentemente muito melhorados com o tratamento pelos derivados do Chaulmoogra [...]" (JUSTA, set 1930: 13).

Além disso, nesses dois artigos, Justa também se refere ao que ele chamou de medicação sintomática, que está relacionado, primeiramente, aos medicamentos para os sintomas da lepra como febre e nevralgias. Mas também são entendidas por Justa como medidas de caráter comportamental que deveriam ser recomendadas aos pacientes, essas se relacionam com higiene, alimentação e exercícios físicos. Ou seja, a terapêutica antileprótica não se resumia apenas a medicamentos, pois também tinha relação com os hábitos diários:

A terapêutica da Lepra é principalmente constituída hoje pelos preparados oleosos do grupo Chaulmoogra e seus derivados (ésteres e sais ou sabões), todos podendo ser administrados por via gástrica ou parental. Subsidiariamente ainda é utilizada a medicação sintomática (higiênica e dietética, cirúrgica e por meio de drogas, internamente ou externamente) (JUSTA, ago 1930: 13).

Com relação à alimentação, Justa aponta que ela deve ser variada e substancial, de acordo com o gosto de cada paciente, mas é absolutamente proibido o consumo de bebidas alcoólicas e nos períodos febris, no qual a doença está mais severa, é recomendada uma dieta líquida, láctea e vegetariana. Os exercícios físicos também são destacados como necessários para a melhor condição do doente, porém, Justa sempre ressalta que eles devem ser compatíveis com as condições e a energia dos enfermos, já que existem casos em que a doença é mais avançada, enquanto em outros ela é mais branda (JUSTA, set 1930).

Embora aborde as recomendações citadas anteriormente, a que recebe mais destaque no artigo são as medidas de caráter higiênico: 
O lázaro deve manter o mais completo asseio corporal, mercê de banhos, de preferência mornos, frequentes e com sabão; [...]. O máximo de cuidado deve haver com qualquer solução de continuidade da pele. O mínimo golpe, a menor escoriação, devem ser desinfetados por meios adequados, com antissépticos brandos [...](JUSTA, set 1930: 12).

Nessas recomendações comportamentais, Justa também não está sozinho, já que outros médicos brasileiros também recomendavam tais práticas. Um exemplo é Souza Araújo, que acreditava que a terapêutica da lepra deveria se basear em um tratamento eclético: "Como tratamento complementar, aconselhava o uso de tônicos, laxantes e diuréticos, e também, a adoção de um regime de farta alimentação, exercícios e repousos metódicos" (SOUZA, 2009: 77).

Letícia Souza não enxerga essas recomendações apenas como algo de caráter essencialmente médico, ela levanta a hipótese de que existia uma intenção de civilizar o doente de lepra, já que enfermidade era vista como doença das classes sociais mais baixas:

Como procurarei mostrar mais adiante, pode-se notar que o isolamento dos doentes no país, não era recomendado apenas como uma estratégia de proteção da sociedade sadia, mas tinha como pressuposto a possibilidade de “civilizar" essa população, dentro de um regime rigoroso e autoritário, onde práticas higiênicas, exercícios físicos e boa alimentação eram tidos, junto com as práticas terapêuticas, como elementos essenciais para o tratamento e bem estar dos doentes (SOUZA, 2009:51-52).

Com relação a Antônio Justa, conseguiu-se encontrar nessa série de artigos alguns indícios de que o médico considerava a lepra uma doença das camadas sociais mais humildes, mas não é possível afirmar se essas recomendações partiam mais de uma intenção de civilizar do que de tratar.

Abordando novamente o tratamento, porém partindo para o próximo artigo, que é dedicado a profilaxia, Justa também aponta algumas considerações sobre a medicação, principalmente com a intenção de justificar uma revisão na política isolacionista:

TERAPÊUTICA E PROFILAXIA de Lepra se associam, e já LEONARD ROGERS proclama com entusiasmo, a breve EXTINÇÃO DA MOLÉSTIA 
EM TODO AQUELE PAÍS EM QUE O ABRANDAMENTO DO ISOLAMENTO E POR ÚLTIMO O SEU ABANDONO, VENHAM FACILITAR CADA VEZ MAIS O DIAGNÓSTICO E O TRATAMENTO PRECOCES, ESTANCANDO ASSIM EM SUA ORIGEM A PROPAGAÇÃO DA MORFEIA (JUSTA, out 1930: 16).

Sabe-se que no Brasil, no período em destaque, a forma mais comum de se tratar a lepra era através do isolamento de doentes. Inclusive, com a aprovação do regulamento sanitário de 1920, que sofreu algumas revisões, sendo posteriormente aprovado pelo decreto de 31 de dezembro de 1923, a lepra passou a figurar como uma das doenças que tinha como principal profilaxia o isolamento compulsório de doentes:

O regulamento de 1920, no caso específico da lepra, não apenas criava esse órgão central para coordenar e implementar a luta profilática em todo país, como também estabelecia as diretrizes básicas - e muitas vezes minuciosas que deveriam orientá-la. Dessa forma, o controle da doença assumia um caráter mais coercitivo e o isolamento, principal medida profilática para o caso da lepra, domiciliar ou nosocomial, tornava-se compulsório (CUNHA, 2005: 51).

Dessa forma, essa foi a orientação nacional para o combate à lepra e, no Ceará, não foi diferente, já que foi efetivada a construção de um leprosário com essa finalidade. Porém, o isolamento compulsório não foi completamente aceito entre a comunidade médica brasileira, gerando divergências na forma em que ele foi praticado.

Esse artigo sobre a profilaxia é destinado basicamente para a discussão do isolamento compulsório de doentes, sobre o qual o médico se demonstra, em certos pontos, contra tal prática, afirmando que os avanços no tratamento com óleo de chaulmoogra possibilitavam uma nova forma de tratar a lepra. Além disso, o médico justifica a revisão da prática isolacionista através de outros pontos já mencionados: primeiro, o fato da lepra, em sua concepção e na de outros médicos, ser uma doença contagiosa através do contato íntimo e prolongado com o doente, ou seja, de difícil transmissão; segundo, que nem todo leproso é contagiante, isto é, nem todo o doente de lepra está transmitindo a doença.

Diante disso, Justa considera que o isolamento deve continuar a ser praticado, mas de forma mais branda: 
O RECENSEAMENTO DOS LEPROSOS não surtirá resultado senão quando executado conjuntamente com o TRATAMENTO e o ISOLAMENTO. Este último, porém, deverá ser tanto quanto possível facultativo e transitório, atenuando-se em regime de liberdade crescente, de sorte a alcançar-se em breve espaço a educação sanitária bastante, a serem socorridos os doentes em AMBULATÓRIOS, CLINICAS ou HOSPITAIS ESPECIAIS, restringindo-se a LEPROSARIA somente aos INDIGENTES, estropiados pela moléstia, impossibilitados de proverem a própria subsistência, e sem se descurar o amparo ás suas famílias. Muito longe estamos no Ceará de alcançarmos tal desidrato, pois na mentalidade popular até na das pessoas de instrução mais avançada, não penetrou ainda quanto de benefício aos doentes e a Coletividade, vieram trazer os RECENTES MÉTODOS DE TRATAMENTO DA LEPRA com o aperfeiçoamento dos PREPARADOS CHAULMOOGRICOS (JUSTA, out 1930: 17).

Então, pelo exposto acima, percebe-se que o médico tem uma postura bem diferente sobre o isolamento comparado ao que era recomendado no já citado regulamento sanitário de 1923. Porém, nessa questão, Justa também não estava sozinho, pois entre os médicos brasileiros também existiam divergências sobre o isolamento de leprosos.

No Brasil, os médicos que prescreviam o isolamento compulsório como profilaxia mais eficaz ficaram conhecidos como segregacionistas. Dentre eles, destacaram-se famosos nomes da medicina nacional, como Oswaldo Cruz, Heráclides César Souza Araújo e Belisário Penna. O outro grupo ficou conhecido como humanitarista, pois prescrevia como profilaxia da doença, o isolamento misto. Este poderia ser realizado no domicílio, quando houvesse condições higiênicas adequadas (era o isolamento típico das classes abastadas) ou em leprosários (era o isolamento destinado aos pobres). Dentre os partidários dessa corrente, Emílio Ribas, Eduardo Rabello e Silva Araujo eram as figuras mais importantes (FERREIRA, 2009: 86).

Justa não se enquadra totalmente em nenhum dos grupos, pois não era segregacionista, já que era contra o isolamento compulsório, mas também não pode ser considerado humanitarista, pois aborda a ideia de um isolamento preferencialmente facultativo, algo que não era pensado nesse segundo grupo. Desse modo, percebe-se Justa com uma postura diferenciada, mais próxima da postura humanitarista. 
O médico ainda relata o quanto a falta de conhecimento sobre a lepra prejudica o seu combate, pois a população impediu a construção de uma creche para os cuidados com os filhos dos leprosos simplesmente por medo do contágio, o que para Justa é infundado, já que a população sã não teria um contato íntimo com os doentes. Isso ocasionou a construção da instituição nas proximidades da leprosaria, o que para Justa é muito negativo pela dificuldade do amparo, já que era longe da capital, e pela saúde das crianças, que, por estarem próximas aos pais, acabavam convivendo intimamente com eles (JUSTA, out 1930).

Dessa forma, Justa constrói um saber médico sobre a lepra buscando desconstruir certas ideias tidas como enraizadas quando se falava na doença, como o fato dela ser vista como uma enfermidade extremamente contagiosa e a ideia do isolamento compulsório como única medida profilática contra a doença, eliminando a terapêutica com base na chaulmoogra. Ou seja, Justa buscou nessa série de artigos, como ele mesmo próprio discorreu, esclarecer a população acerca da lepra, mostrando que ela era contagiosa sim, mas precisava de condições específicas para isso e ainda alertando que o isolamento, especialmente o compulsório, precisava ser revisto, dando espaço para o uso da terapêutica como a forma principal de combate à doença: "Do exposto depreende-se com evidencia que a Profilaxia da Lepra mais se deve basear no DIAGNÓSTICO e no TRATAMENTO DOS CASOS PRECOCES, DO QUE NO ISOLAMENTO, SOBRETUDO NO ISOLAMENTO COMPULSÓRIO” (JUSTA, out 1930: 19).

O último artigo dessa série trata-se do que Justa denominou de "Observações", que se refere a resumos sobre alguns pacientes internados, nos quais o médico aponta algumas considerações sobre a doença que ajudam a justificar e legitimar o seu discurso. Um exemplo interessante é de uma menina leprosa que a família toda se contaminou com a doença:

Az.M.B, parda, s.f. 9 anos natural e residente em Jaguaribe-mirim (Ceará) donde veio para a Leprosaria - (Ficha 135). Irmã dos precedentes (131132-133-134). Parece ter adoecido em 1928 [...]. NOTA: Cinco irmãos leprosos, residentes na mesma casa, na mesma localidade, donde nunca se ausentaram. O primeiro caso verificou-se há 9 anos, em 1920, tendo a paciente 12 anos de idade; 6 anos depois verifica-se o segundo caso em uma jovem de 17 anos; um anos depois, outro, em um menos de 8 anos e 
nova caso no ano seguinte em uma menor de 8 anos, igual espaço de tempo decorrido, nova vítima, sendo esta de 14 anos. Tem-se a impressão de que os germes foram se tornando mais abundantes ou mais virulentos nas sucessivas passagens ou ambas as coisas... (JUSTA, nov 1930: 12).

Dessa forma, entende-se que o médico utiliza esse caso para demonstrar a teoria que acreditava do contágio através de um contato íntimo e prolongado, como foi o caso dessa família, que, além disso, tinha como agravante, na opinião de Justa, o grande número de doentes, o que podia facilitar o contágio. Pode-se perceber que os dados apontados por Justa demonstram justamente isso, pois quando existia apenas um doente, demorou 6 anos para outra pessoa adoecer, mas quando tinha 2 doentes, o caso aparecia com intervalo de um ano, e com 3 e 4 doentes, a mesma situação. Então, o médico buscou comprovar, através de dados, as suas teorias.

O conhecimento de Justa apresentado nessas páginas trata-se de seus pensamentos iniciais sobre a doença, já que o médico continuou envolvido com os problemas sobre a lepra até a sua morte, em 1941. Devido a isso, permaneceu escrevendo sobre ela, e seus discursos, com o tempo, se fortaleceram e se tornaram mais radicais, pois o médico continuou acreditando na pouca contagiosidade e na necessidade do abrandamento do isolamento de leprosos, afirmando agora que os casos nãocontagiantes não precisavam ser isolados (JUSTA; PORTO, mai 1940). A única postura de Justa que se percebe uma grande mudança é com relação ao óleo de chaulmoogra, pois, apesar de toda essa empolgação inicial com o tratamento, com o decorrer dos anos, o médico se mostra cada vez mais desconfiado sobre a sua eficácia, afirmando que o medicamento só tem efeito positivo principalmente nos casos iniciais de lepra e se for utilizado em conjunto com uma boa alimentação, higiene e exercícios físicos. (JUSTA, mai 1931).

O fato de Justa disseminar o seu discurso e ter grande influência no combate à doença, devido ao papel que desempenhava no leprosário, não quer dizer que a lepra foi tratada da forma que ele desejava e que a sociedade aceitou melhor a presença dos enfermos acometidos por essa doença. Como exemplo, Antônio Ferreira (2011) mostra que a imprensa continuou a retratar a lepra como uma moléstia altamente contagiosa, o que gerava medo entre a população.

Contudo, Justa teve sim a sua influência, mas não se pode afirmar que o isolamento de leprosos no Ceará funcionou apenas para casos contagiosos e/ou 
indigentes, ou que o mesmo ocorreu de forma completamente facultativa, já que através dos prontuários médicos da colônia Antônio Diogo foi possível mapear essas questões que, embora não seja o objetivo desse ensaio, merecem ser mencionadas a título de esclarecimento. Foi possível perceber que o isolamento, em sua maioria, era para as pessoas mais pobres e ainda a presença de muitos casos nos quais os pacientes procuraram a instituição para se isolar de forma voluntária. Entretanto, não se pode falar em isolamento completamente facultativo, pois são casos isolados, além do próprio meio social ter funcionado como um "incentivo" ao isolamento, principalmente dos mais pobres, como também reflete Antônio Ferreira:

Mesmo sem dados quantitativos em relação aos internamentos, pode-se sugerir que o seu caráter "voluntário" deve ter sido considerável. Sendo a grande maioria dos leprosos constituída por pobres, muitos dele indigentes, sem nenhuma perspectiva futura, experimentando na prática uma morte social, o leprosário aparecia para esse grupo como a única alternativa para uma morte menos humilhante (FERREIRA, 2011: 202).

\section{Considerações Finais}

Pelo exposto apresentado nestas páginas, foi possível perceber a forma diferenciada que Antônio Justa abordou a lepra ainda nos anos iniciais de suas experiências mais profundas com a enfermidade e seus doentes.

O médico, mesmo com a sua pouca experiência, procurou pesquisar e trazer para o Ceará uma nova forma de se ver a doença, na qual ela não era o sinônimo de perigo, devido ao contágio, mas sim uma enfermidade que podia ser evitada se algumas recomendações fossem seguidas, como a diminuição do contato íntimo e prolongado entre sadios e leprosos.

Além disso, Justa também levantou a ideia de que o isolamento compulsório não era o correto e que a profilaxia da lepra deveria ter por base o tratamento medicamentoso, e não o isolamento compulsório, já que considerava que ele deveria ser aplicado apenas para alguns casos e ainda de forma facultativa.

O interessante de analisar esses pensamentos iniciais de Justa sobre a lepra é perceber que o médico já tinha uma postura diferenciada sobre a enfermidade, mesmo 
com a pouca experiência possuída. E que, embora esses sejam discursos iniciais, a maioria deles só se fortalece no decorrer dos anos de sua vida e experiência com a doença, o que nos faz concluir que essa série de artigos analisados funcionou como a raiz do saber médico que Antônio Justa produziu sobre a lepra no Ceará durante os anos que seguem.

\section{Fontes}

JUSTA, Antônio (1929). A lepra. Ceará Médico, Fortaleza, ano VIII, n. 9 e 10, set/out, pp. 2-4.

(1930). A lepra II - Epidemiologia. Ceará Médico, Fortaleza, ano IX, n. 5, maio pp. 11-16.

(1930). A lepra III - Sintomalogia Diagnostico. Ceará Médico, Fortaleza, ano IX, n. 6, junho, pp.16-19.

(1930). A lepra III - Sintomalogia Diagnostico (conclusão). Ceará Médico, Fortaleza, ano IX, n 7, julho, pp. 4-6.

(1930). A lepra IV - Tratamento. Ceará Médico, Fortaleza, ano IX, n. 8, agosto, pp.16-18.

(1930). A lepra IV - Tratamento (conclusão). Ceará Médico, Fortaleza, ano IX, n. 9, setembro, pp.9-14.

(1930). A lepra V - Profilaxia. Ceará Médico, Fortaleza, ano IX, n.10, outubro, pp.16-19.

(1930). A lepra VI - Observações. Ceará Médico, Fortaleza, ano IX, n.11, novembro, pp. 9-15.

(1931). O problema da lepra no Ceará. Ceará Médico, Fortaleza, ano X, n. 5, maio, pp.6-12.

; Valter, PORTO (1940). A luta contra a lepra no Ceará. Ceará Médico, ano XX, número 5, maio, pp. 24-27.

MOTA, João (1952). Médicos cearenses. Ceará Médico, ano XX, n.1-3, jan/mar, pp.1719.

\section{Referências Bibliográficas}

BARBOSA, José (1994). História da saúde pública do Ceará: da Colônia a Vargas. Fortaleza: UFC.

CUNHA, Vívian (2005). O isolamento compulsório em questão: políticas de combate à lepra no Brasil (1920-1941). Dissertação (Mestrado em História das Ciências e da Saúde). Fundação Oswaldo Cruz, Rio de Janeiro.

FERREIRA, Antônio (2011). "Lazaropolis": a lepra entre a piedade e medo (Ceará, 1918-1935). Dissertação (Mestrado em História) - Universidade Federal do Ceará, Fortaleza.

GADELHA, Georgina (2012). Sob o signo da distinção: formação e atuação da elite médica cearense (1913-1928). Tese (Doutorado em História das Ciências e da Saúde) - Fundação Oswaldo Cruz, Rio de Janeiro. 
GARCIA, Ana (2011). A ciência na saúde e na doença: atuação e prática dos médicos em Fortaleza (1900-1935). Tese (Doutorado em História Social) - Pontifícia Universidade Católica de São Paulo, São Paulo.

HANSENÍASE (2015). Disponível em: http://www.sbd.org.br/doencas/hanseniase/ Acesso em: 10 set. 2015.

MACIEL, Laurinda (2007). "Em proveito dos sãos, perde o lázaro a liberdade”: uma história das políticas públicas de combate à lepra no Brasil (1941-1962). Tese (Doutorado em História) - Universidade Federal Fluminense, Niterói.

PINHEIRO, Francisca (2013). "Não esperemos só pela ação do governo, a calamidade é pública”: a atuação do jornal O Nordeste no combate à lepra em Fortaleza (1922-1930). Monografia (Licenciatura em História) - Universidade Estadual do Ceará, Fortaleza.

SCHNEIDER, Silvia (2011). Lepra: fotografia e discurso na obra de Souza-Araújo (1916-1959). Dissertação (Mestrado em História) - Universidade Estadual do Oeste do Paraná, Marechal Cândido Rondon.

SOMBRA, Waldy (1999). Rodolfo Teófilo: o Varão Benemérito. Fortaleza: Casa de José de Alencar/ Programa Editorial.

SOUZA, Letícia (2009). Sentidos de um "país tropical": a lepra e a chaulmoogra brasileira. Dissertação (Mestrado em História das Ciências e da Saúde) Fundação Oswaldo Cruz, Rio de Janeiro.

Artigo recebido em 20 de fevereiro de 2016.

Aprovado em 25 de março de 2016.

DOI: 10.12957/intellectus.2016.21656 